\title{
Potential and problems in ultrasound-responsive drug delivery systems
}

\author{
This article was published in the following Dove Press journal: \\ International Journal of Nanomedicine \\ 19 April 2013 \\ Number of times this article has been viewed
}

\author{
Ying-Zheng Zhao',3 \\ $\mathrm{Li}-\mathrm{Na} \mathrm{Du}^{2}$ \\ Cui-Tao Lu' \\ Yi-Guang Jin² \\ Shu-Ping $\mathrm{Ge}^{3}$ \\ 'Wenzhou Medical College, Wenzhou \\ City, Zhejiang Province, ${ }^{2}$ Department \\ of Pharmaceutical Sciences, Beijing \\ Institute of Radiation Medicine, \\ Beijing, People's Republic of China; \\ ${ }^{3}$ St Christopher's Hospital for \\ Children/Drexel University College \\ of Medicine, Philadelphia, PA, USA
}

Correspondence: Cui-Tao Lu Wenzhou Medical College, Wenzhou City, Zhejiang Province 325035, People's Republic of China

Tel + I58 58556100

Email Ictuua@sina.com

Shu-Ping Ge,

St Christopher's Hospital for Children/

Drexel University College of Medicine,

Philadelphia, PA 19134, USA.

Email 2440623174@qq.com

\begin{abstract}
Ultrasound is an important local stimulus for triggering drug release at the target tissue. Ultrasound-responsive drug delivery systems (URDDS) have become an important research focus in targeted therapy. URDDS include many different formulations, such as microbubbles, nanobubbles, nanodroplets, liposomes, emulsions, and micelles. Drugs that can be loaded into URDDS include small molecules, biomacromolecules, and inorganic substances. Fields of clinical application include anticancer therapy, treatment of ischemic myocardium, induction of an immune response, cartilage tissue engineering, transdermal drug delivery, treatment of Huntington's disease, thrombolysis, and disruption of the blood-brain barrier. This review focuses on recent advances in URDDS, and discusses their formulations, clinical application, and problems, as well as a perspective on their potential use in the future.
\end{abstract}

Keywords: ultrasound, targeted therapy, clinical application

\section{Introduction}

Creating a drug delivery system that responds to a stimulus exerted by an external force or produced by the target tissue itself is of great research interest. Many physical and chemical stimuli in the microenvironment, such as heat, magnets, enzymes, and $\mathrm{pH}$, can be used as triggers. ${ }^{1}$

Ultrasound consists of pressure waves at frequencies of $20 \mathrm{kHz}$ or greater. Like optical and audio waves, ultrasonic waves can be focused, reflected, and refracted through a medium. As a mature medical technology, ultrasound imaging can be used repeatedly without concern about residual radiation. ${ }^{2}$ Therefore, ultrasound imaging is acceptable to most patients and the equipment involved is generally less expensive than that of other imaging technologies.

However, blood is a poor scatterer of ultrasound waves at clinical diagnostic transmitting frequencies, which lie between $1 \mathrm{MHz}$ and $40 \mathrm{MHz}$. To enhance contrast in ultrasound imaging, so-called ultrasound contrast agents, consisting of gas encapsulated in biodegradable shells, have been developed. With their gas-nuclear structure, ultrasound contrast agents can oscillate in ultrasonic pressure with volume expansion and contraction. This phenomenon is known as acoustic cavitation. ${ }^{3}$

Cavitation at a higher ultrasonic pressure will result in more violent oscillation of ultrasound contrast agents, leading eventually to their destruction. When drugs are loaded into ultrasound contrast agents, acoustic cavitation can be used as a trigger to release drugs at desired sites. ${ }^{4-7}$

In recent times, drug-loaded ultrasound contrast agent systems, also termed ultrasound-responsive drug delivery systems (URDDS), have become an increasing 
focus of research. URDDS include microbubbles, ${ }^{8-10}$ nanobubbles, ${ }^{11,12}$ nanodroplets, ${ }^{13}$ liposomes, ${ }^{14,15}$ emulsion, ${ }^{16}$ and micelles. ${ }^{17-19}$ A combination of two or more formulations can be used as URDDS, such as liposomal bubbles $^{20,21}$ and microemulsions. ${ }^{22}$ The drugs loaded can include inorganic substances, eg, titanium dioxide, ${ }^{23}$ small molecules (curcumin, ${ }^{24}$ doxorubicin, ${ }^{25}$ cisplatin, ${ }^{5}$ epirubicin hydrochloride, ${ }^{26}$ 10-hydroxycamptothecin ${ }^{27}$ ), proteins, ${ }^{28,29}$ small interfering RNA,,${ }^{8,21}$ DNA, ${ }^{30}$ and antisense oligodeoxynucleotides. ${ }^{31,32}$ Their therapeutic applications include anticancer therapy, ${ }^{23,33}$ treatment of ischemic myocardium, ${ }^{29}$ induction of an immune response, ${ }^{34}$ cartilage tissue engineering, ${ }^{35}$ transdermal drug delivery, ${ }^{36,37}$ treatment of Huntington's disease ${ }^{38}$ and thrombolysis, ${ }^{39,40}$ and disruption of the blood-brain barrier. ${ }^{41,42}$ This review focuses on recent advances in URDDS, and discusses their formulations, clinical applications, and problems, with a perspective on their potential use in the future.

\section{Multiple ultrasound-responsive drug delivery systems \\ Microbubbles}

Ultrasound exposure alone had been proven to enhance cell membrane permeability, ${ }^{43}$ and addition of microbubbles has a significant potentiating effect. ${ }^{31}$ If cells are located in close proximity to gas-filled microbubbles which serve as cavitation nuclei, permeability of the cell membrane will be increased. ${ }^{6,44}$ In the last decade, microbubble agents have been investigated as carriers for systemic drug administration. Plasmid DNA and other therapeutic materials may adhere to the microbubbles or be packed into the microbubbles, which is beneficial for targeted drug delivery. The possible mechanism of gene transfection or targeted drug delivery is related to sonoporation. High-speed microstreams or microjets cause shear stress on the cell membrane, and transient nonlethal holes appear in the membrane. The pressure gradient and shear stress enhance the permeability of the cell membrane, enabling transport of plasmid DNA or therapeutics into the cell. ${ }^{30}$

As shown in Figure $1 \mathrm{~A}$, microbubbles are one type of widely used ultrasound contrast agent, and are microsized $(1-10 \mu \mathrm{m})$ gas bubbles with a shell composed of phospholipids, polymers, or proteins (Table 1). First-generation microbubbles are air-filled microspheres, with mean diameters in the range of $1-8 \mu \mathrm{m}$, that are capable of passing through pulmonary capillaries. However, these air-filled microbubbles disappear from the bloodstream rapidly because of low resistance to arterial pressure gradients and the high solubility of air in blood. ${ }^{45}$ Therefore, second-generation contrast agents have been developed using microbubbles filled with high molecular weight hydrophobic gases, including perfluorocarbons or sulfur hexafluoride (Figure 1A). Surfactants, albumin, and phospholipids are used to form the bubble shell in order to improve stability in the bloodstream. Sonazoid ${ }^{\circledR}$ (GE Healthcare, Chalfont, UK), a phosphatidylserine microbubble agent filled with perfluorobutane, is a contrast agent specifically targeted to tumor tissue in the liver. ${ }^{46,47}$ Sonazoid is taken up by Kupffer cells (macrophages) in the liver, enhancing contrast in the liver parenchyma within about 10 minutes of injection, whereas the contrast effects in tumors that lack Kupffer cells are not enhanced. ${ }^{47}$ Sonazoid has been commercially available in Japan since 2007.

Microbubbles are a suitable ultrasound contrast agent because they can interact with the ultrasound wave. ${ }^{48}$ Since the 1990s, a number of research groups have designed drugloaded microbubbles. As shown in Figure 2, their advantages include visualization of drug-loaded microbubbles with low acoustic pressures, ie, image-guided drug delivery; protection of biopharmaceuticals, such as proteins and nucleic acids, against being degraded on administration; targeted drug delivery to specific tissue (ie, tissue that is exposed to

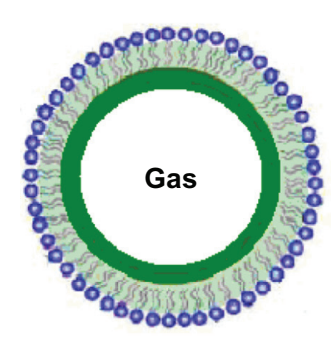

A

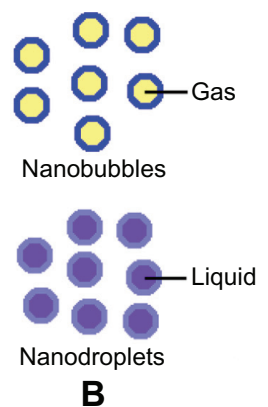

B

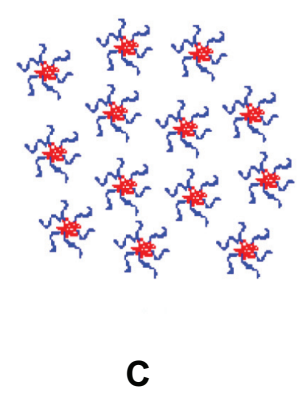

C

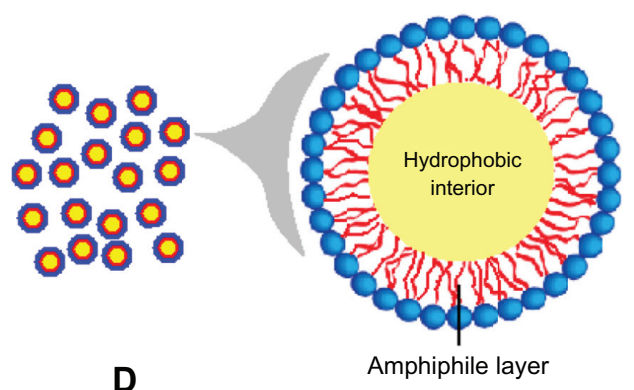

D

Figure I Schematic illustration of various ultrasound-responsive drug delivery systems. (A) Microbubbles, (B) nanobubbles and nanodroplets, (C) polymeric micelles, and (D) microemulsions. 
Table I Main commercially available ultrasound contrast agents

\begin{tabular}{lllll}
\hline Name & Shell & Filled gas & Size $(\mu \mathrm{m})$ & Manuracturer \\
\hline Albunex $^{\circledR}$ & Albumin & Air & 4.3 & Hafslund nycomed \\
Levovist $^{\circledR}$ & Galactose & Air & $2-4$ & Schering \\
Optison $^{\circledR}$ & Albumin & Perfluoropropane & $3-32$ & GE Healthcare \\
Definity $^{\circledR}$ & Lipids & Perfluoropropane & I.I-20 & Lantheus medical imaging \\
Imagent $^{\circledR}$ & Lipids & Perfluoropropane & 5 & Alliance pharmaceutical corporation \\
Sonovue $^{\circledR}$ & Lipids & Sulfur hexafluoride & 2.5 & Bracco \\
Sonazoid $^{\circledR}$ & Lipids & Perfluorobutane & $2-3$ & GE Healthcare \\
\hline
\end{tabular}

ultrasound) and thus reducing side effects; and enhanced uptake by cells via the cavitation effect upon exposure to ultrasound.

Methods used to prepare drug-loaded microbubbles include association of drugs with the shell, ${ }^{25}$ covalent linkage with the building blocks, and drug encapsulation in an oil reservoir within the core of the microbubble. ${ }^{24}$ Another preparation method involves packing the drug into nanoparticles, which are subsequently attached to the surface of the microbubble. ${ }^{49}$

\section{Nanobubbles and nanodroplets}

A major disadvantage of microbubbles as drug delivery systems is their relatively large size $(1-10 \mu \mathrm{m})$, which is a problem for microbubbles needing to penetrate through the epithelial cells of the vasculature to the target tissue. On intravenous injection, microbubbles are infused into the circulation and eventually become trapped in the lungs where gas exchange occurs. Therefore, drug-loaded microbubbles are mainly restricted to cardiovascular targets and tumor endothelium.

To overcome this limitation, nanobubbles ${ }^{11,20}$ and nanodroplets ${ }^{13}$ with sizes smaller than $1 \mu \mathrm{m}$ have been developed (Figure 1B). Nanobubbles are generally prepared by sonicating in the presence of a fluorinated gas, such as perfluorocarbons or sulfur hexafluoride. This method has been used successfully in the delivery of plasmid DNA, small interfering RNA, and coumarin. ${ }^{11}$ With their low boiling points, fluorocarbon gases can be evaporated easily on exposure to the thermal effects of ultrasound. For example, a liquid fluorocarbon can be emulsified in water at a nanoscale particle size and vaporized into gas bubbles. ${ }^{50,51}$ Via the enhanced permeability and retention effect, these nanoscale droplets can penetrate into tumor tissue after intravenous administration. ${ }^{52}$ When ultrasound is focused on the tumor tissue, a liquid to gas phase transition occurs because of the thermal effect, and ultrasonic microbubbles are formed in situ. ${ }^{53}$

\section{Polymeric micelles}

As shown in Figure 1C, polymeric micelles are formed spontaneously in aqueous solutions containing amphiphilic block copolymers and have a core-shell architecture. Self-assembly occurs when the copolymer concentration reaches a threshold value, known as the critical micelle concentration. The size of polymeric micelles varies from $10 \mathrm{~nm}$ to $100 \mathrm{~nm}$. In previously reported research, release of doxorubicin from Pluronic micelles was influenced by

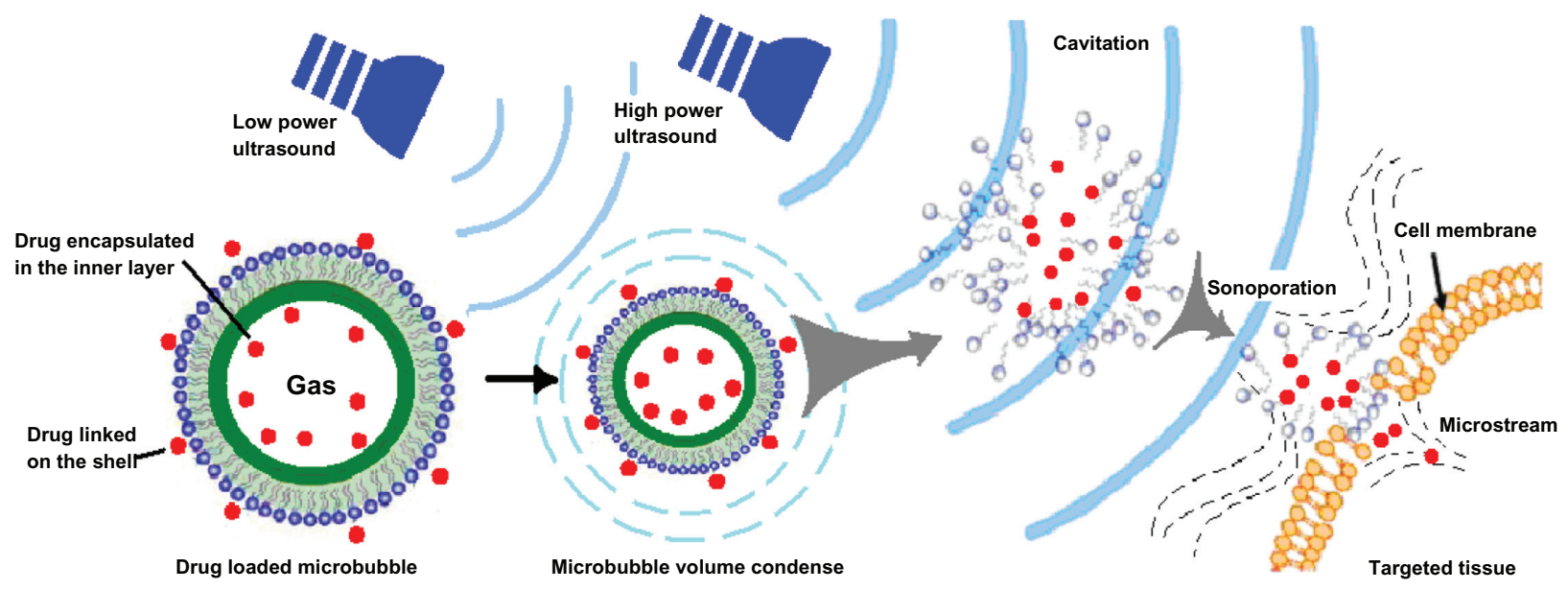

Figure 2 Illustration of the wide potential of drug-loaded microbubbles. 
high-frequency ultrasound. ${ }^{19}$ Onset of transient cavitation and release of doxorubicin from micelles were observed at much higher power densities than at low-frequency ultrasound $(20-100 \mathrm{kHz})$. Even a short exposure to high-frequency ultrasound of 15-20 seconds can significantly enhance the intracellular uptake of Pluronic micelles.

Other research has demonstrated that continuous wave and pulsed ultrasound enhances uptake of doxorubicin from phosphate-buffered solution and from Pluronic micelles. ${ }^{17}$ The main factor influencing drug uptake is density of the ultrasound, with drug uptake being enhanced with increasing power. These observations imply two independent mechanisms controlling acoustic activation of drug uptake from Pluronic micelles. The first is acoustically triggered drug release from micelles, that results in a higher concentration of free drug in the incubation medium. The second mechanism is based on the perturbation of cell membranes, resulting in increased uptake of the drug encapsulated within the micelles.

Other researchers have investigated the chemical conjugation of doxorubicin with polymeric micelles, ${ }^{54}$ which were found to enhance the antitumor activity of doxorubicin and to circumvent multidrug resistance in A549 cells (Figure 3). With their low critical concentration, high loading efficiency, diameter in the nano-range, good penetration ability, and controlled-release behavior, polymeric micelles might be developed as a new type of URDDS for cancer therapy.

\section{Microemulsions}

A microemulsion is a system of water, oil, and an amphiphile, and exists a single optically isotropic and thermodynamically stable liquid solution (Figure 1D). Surfactant molecules that stabilize microemulsions are often the same as those that form micelles. Accumulation of microemulsions in tumor tissue has been confirmed by ultrasound imaging.
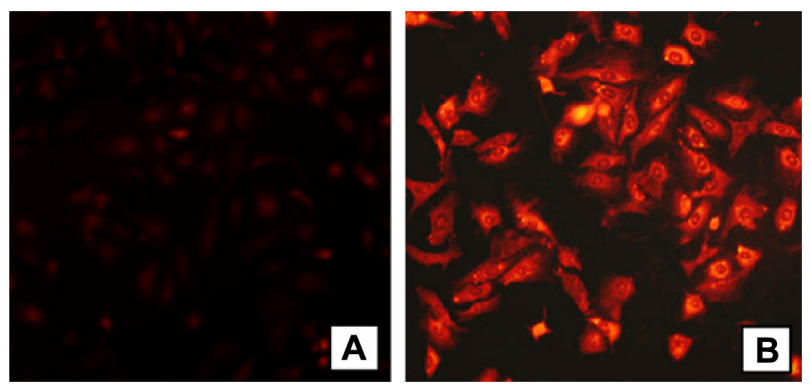

Figure 3 Fluorescence microscopy of A549 cells containing doxorubicin polymeric micelles, (A) A549 cells incubated with free doxorubicin and (B) A549 cells incubated with polymeric micelles conjugated with doxorubicin.

Note: Doxorubicin concentration $=10 \mu \mathrm{g} / \mathrm{mL}$. Copyright (c) 2011. Elsevier. Reproduced with permission from Zhao Y, Sun C, Lu C, et al. Characterization and anti-tumor activity of chemical conjugation of doxorubicin in polymeric micelles (DOX-P) in vitro. Cancer Lett. 2011;311:187-194.54
Rapoport et al have reported that a paclitaxel-loaded microemulsion converted into microbubbles locally in tumor tissue under the action of tumor-directed therapeutic ultrasound. ${ }^{22}$ Systemic injection of a drugloaded microemulsion combined with therapeutic ultrasound achieved dramatic regression of ovarian, breast, and orthotopic pancreatic tumors in animal experiments, indicating efficient ultrasound-triggered drug release from nanodroplets accumulated in the tumor. No curative effect of the nanodroplet-ultrasound combination was observed without the drug, indicating that the therapeutic effect was attributable to the ultrasound-enhanced chemotherapeutic action of the tumor-targeted drug, rather than the mechanical or thermal action of ultrasound itself.

Curcumin, an important natural antioxidant and anticancer compound, can be stably entrapped into microemulsion droplets of average size $20-35 \mathrm{~nm} .^{24}$ To release curcumin, low frequency $(40 \mathrm{kHz})$ ultrasound at an intensity of $3.8 \mathrm{~W} / \mathrm{cm}^{2}$ or $9.8 \mathrm{~W} / \mathrm{cm}^{2}$ was applied to the microemulsion using a probe sonicator. On insonation, much of the curcumin was released from the microemulsion. The initial release rate (assayed by rate of change in absorption) was as high as $0.11 \mu \mathrm{g}(1.87 \%)$ per second in phosphate-buffered saline solution at neutral $\mathrm{pH}$, but decreased at acidic $\mathrm{pH}$. Although the cargo in a microemulsion is partitioned rather than encapsulated (for example, in liposomes), microemulsions might be feasible for some types of ultrasonic-responsive drug delivery.

\section{Clinical application of URDDS Transdermal drug delivery}

Use of ultrasound to deliver drugs more efficiently through the skin is referred to as sonophoresis. ${ }^{55}$ In earlier studies, the ultrasound used most often was high-frequency sonophoresis (frequencies $\geq 0.7 \mathrm{MHz}$ ). Typical enhancement of skin penetration using high-frequency sonophoresis was about 1-10-fold. ${ }^{56}$ Because the cavitation effect correlated negatively with the frequency of the ultrasound, ${ }^{57}$ Mitragotri et al hypothesized that low-frequency sonophoresis $(20-100 \mathrm{kHz})$ should be more effective in enhancing skin permeability ${ }^{56}$ It was shown that low-frequency sonophoresis at $20 \mathrm{kHz}$ was three orders of magnitude more efficient than high-frequency sonophoresis at $1 \mathrm{MHz}$.

Parameters influencing sonophoresis include the ultrasound duty cycle (ratio of the time that ultrasound is on), distance between the ultrasonic horn and the skin, treatment duration, and composition of the ultrasound coupling medium (ie, an aqueous solution or a gel-like formulation). Commonly used ultrasound duty cycles are $10 \%$ (eg, 0.1 second on and 0.9 second off), ${ }^{58,59} 50 \%$ (eg, 5 seconds on and 5 seconds 
off), ${ }^{36,60,61}$ or continuous application..$^{62,63}$ The horn-to-skin distances used range from the ultrasound horn being in direct contact with the skin (zero distance) to $4.0 \mathrm{~cm} .{ }^{62}$ The most common distance with low-frequency sonophoresis ranges from $0.3 \mathrm{~cm}$ to $1.0 \mathrm{~cm},{ }^{63-65}$ and is much smaller than for high-frequency sonophoresis. Treatment times can vary from a few seconds ${ }^{66,67}$ to a few minutes, ${ }^{36,60}$ to hours to days. ${ }^{58,68}$ The viscosity, surface tension, density, acoustic impedance, and other bulk and interfacial properties of the coupling medium play an important role in enhancement of skin permeability.

\section{Disruption of blood-brain barrier}

The blood-brain barrier is the brain's first line of defense against harmful substances in the blood stream, and is composed of endothelial cells supported by neurovascular cells. The capillary network in the brain is dense (forming an area of about $20 \mathrm{~m}^{2}$ per $1300 \mathrm{~g}$ of human brain). ${ }^{69}$ Transport across the blood-brain barrier involves movement across the luminal and abluminal membranes of the capillary endothelium. The adjacent endothelial cells are cemented together by tight junctions, preventing involvement of the paracellular pathway.

Targeted ultrasound-induced disruption of the bloodbrain barrier may offer a solution to the problem of delivery of small-molecule and large-molecule drugs to the brain. Ultrasound-based techniques could be used in clinical experiments for most disorders of the central nervous system. Thresholds for disruption of the blood-brain barrier have been estimated to be $0.69,0.47$, and 0.36 MPafor $0.1,1$ and 10 msec bursts, respectively. ${ }^{41}$

For example, focused ultrasound significantly enhanced penetration of 1,3-bis(2-chloroethyl)-1-nitrosourea (BCNU) through the blood-brain barrier in normal brains (by 340\%) and tumor-implanted brains (by 202\%) without causing hemorrhage. ${ }^{42}$ Treatment of tumor-implanted rats with focused ultrasound alone had no beneficial effect on tumor progression or on animal survival up to 60 days, and administration of BCNU only transiently controlled tumor progression. However, compared with untreated controls, animal survival was improved by treatment with BCNU only (increase in median survival time [IST ${ }_{\text {median }}$ ], 15.7\%, $P=0.023$ ). Treatment with focused ultrasound before administration of BCNU demonstrated controlled tumor progression $\left(0.05 \pm 0.1 \mathrm{~cm}^{3}\right.$ versus $0.28 \pm 0.1 \mathrm{~cm}^{3}$, day 31$)$ and improved animal survival when compared with untreated controls ( IST $_{\text {median }}, 85.9 \%, P=0.0015$ ).

In a study of Rhesus macaques, McDannold et al evaluated whether an intravenously circulating microbubble agent combined with ultrasound could be applied safely, reliably, and in a controlled manner to temporarily permeabilize the blood-brain barrier. ${ }^{70}$ All animals in this study recovered from each ultrasound session without behavioral deficits, visual deficits, or loss of visual acuity. Disruption of the blood-brain barrier using this clinical strategy was reliably and repeatedly produced without evidence of histological or functional damage in this clinically relevant animal model.

\section{Therapy for thrombotic disease}

Advances in ultrasound-guided delivery of therapy for thrombotic disease have been encouraging. A novel nanosized delivery system for tissue-type plasminogen activator ( $\mathrm{t}-\mathrm{PA}$ ) was designed that suppressed the thrombolytic activity of t-PA, which recovered only when exposed to ultrasound. ${ }^{71}$ t-PA-cationized gelatin and PEGylated gelatin was used to form nanosized complexes by simple mixing with PEG chains. The t-PA activity in the PEGylated complexes was suppressed significantly to $45 \%$ that of nonmodified t-PA. However, when exposed to ultrasound in vitro, the activity of t-PA recovered fully. The half-life of the complexed t-PA in the circulation was prolonged by approximately threefold. Further, in a rabbit model of thrombosis, intravenous administration of PEGylated complexes followed by exposure to ultrasound resulted in complete recanalization, which was in marked contrast with administration of the complex alone. It was concluded that the PEG-modified complex is a promising delivery system for t-PA which can enhance biological activity at the target site when local ultrasound irradiation is used.

In another study, urokinase-type plasminogen activator was encapsulated in hollow nanogels in the size range of 200-300 nm, and found to have a longer circulation time than that of the naked urokinase in vivo. ${ }^{39}$ Protein release could be triggered more rapidly under diagnostic ultrasound conditions at $2 \mathrm{MHz}$, and significantly enhanced thrombolysis of clots. These results are promising in terms of increasing the specificity and positive effects of thrombolytic agents, such as recombinant tissue plasminogen activator, in the treatment of ischemic vascular disease.

Most ischemic heart disease results from thrombotic disease. Zhao et al investigated the cardioprotective effect of acidic fibroblast growth factor combined with heparinmodified microbubbles (aFGF-HMB) using an ultrasound technique (Figure 4A). ${ }^{29}$ Echocardiography of the heart parenchyma was enhanced after injection of aFGF-HMB. The aFGF-HMB suspension demonstrated a good cardioprotective effect in ultrasonic contrast imaging of the heart. M-mode echocardiography showed that a combination 
A

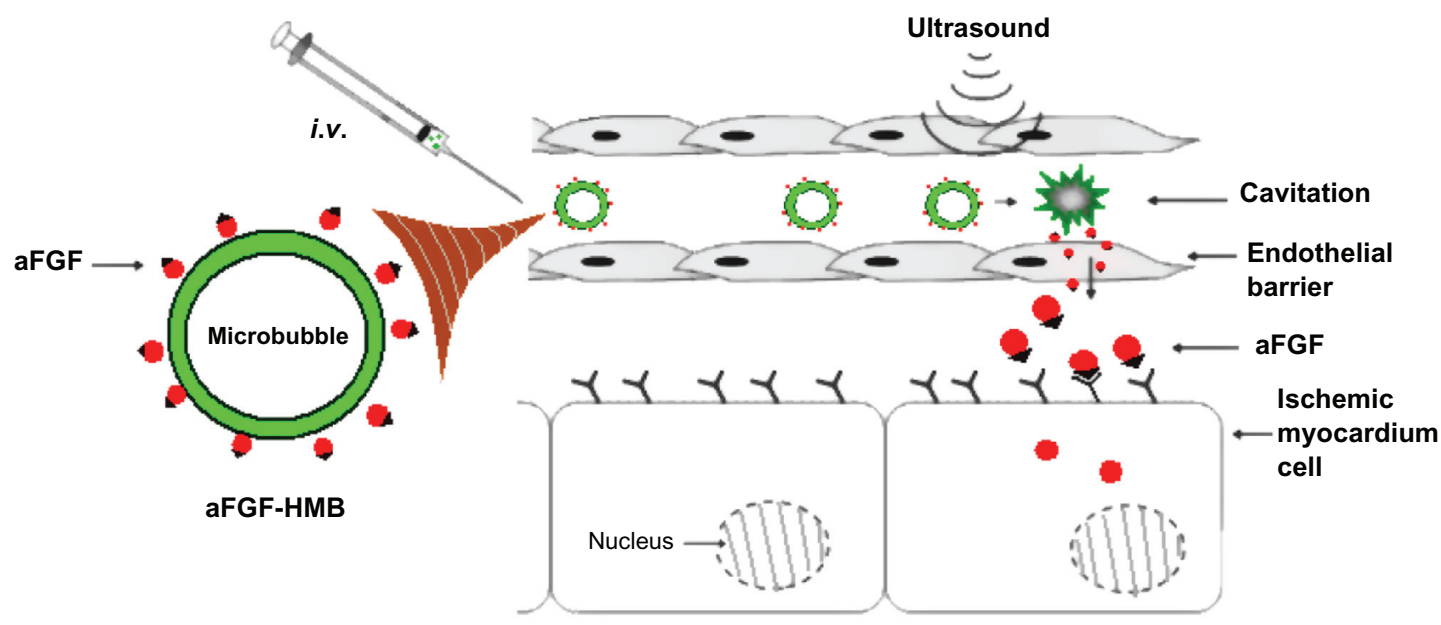

B
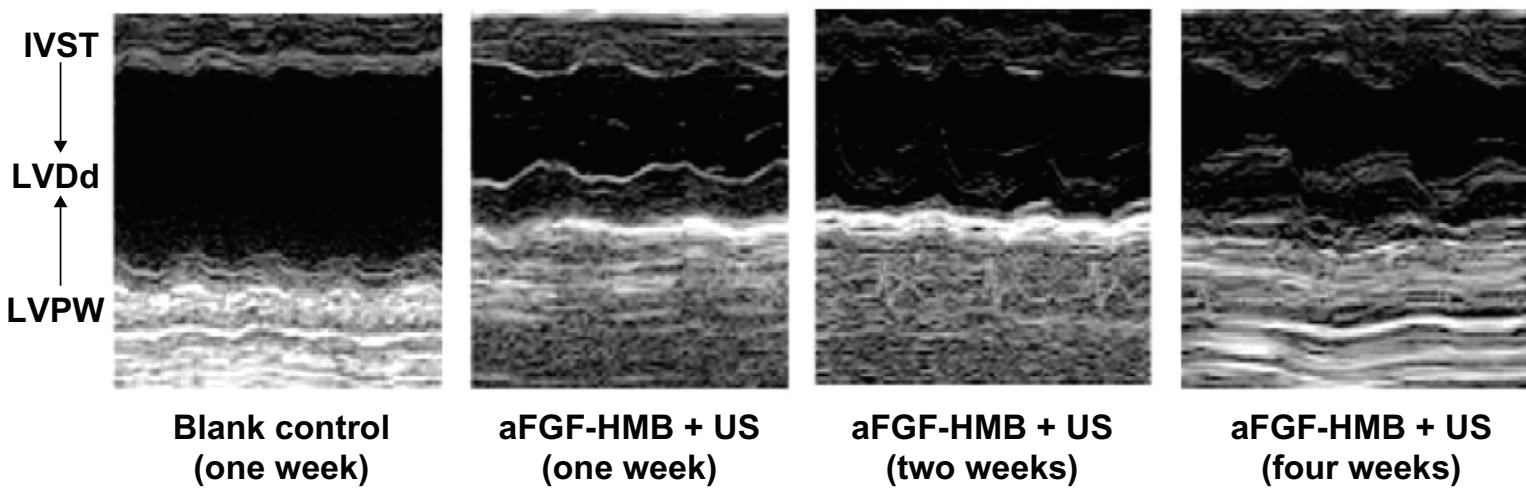

Figure 4 Improving intravenous delivery of acidic fibroblast growth factor to the ischemic myocardium by heparin-modified microbubbles (aFGF-HMB) combined with the UTMD technique. (A) Illustration of the method of administration. (B) M-mode echocardiography for the group that received aFGF-HMB combined with US (ultrasound). ${ }^{29}$ Note: Copyright (c) 2012. Informa Healthcare. Reproduced with permission from Zhao Y, Lu C, Li X, et al. Improving the cardio protective effect of aFGF in ischemic myocardium with ultrasound-mediated cavitation of heparin modified microbubbles: preliminary experiment. J Drug Target. 20I2;20:623-63।.29

Abbreviations: IVST, intraventricular septum thickness; LVDd, left ventricular diastolic dimension; LVPW, left ventricular posterior wall; UTMD, ultrasound-targeted microbubble destruction.

of aFGF-HMB and ultrasound markedly stimulated neogenesis in myocardial vessels, resulting in significant improvement of both regional and global contractile function in the myocardium (Figure 4B).

\section{Drug delivery to tumor tissue}

URDDS have been used to induce apoptosis in tumor-targeted therapy. ${ }^{15,22,26}$ There are two ultrasound-induced effects in this respect, ie, thermal and nonthermal (such as radiation pressure and cavitation). Relatively low temperatures (about $43^{\circ} \mathrm{C}$ ) for $30-60$ minutes can be used for hyperthermia ${ }^{72}$ to sensitize tumors to chemotherapy and radiotherapy. At higher temperatures $\left(>60^{\circ} \mathrm{C}\right)$, ultrasound may be used for thermal ablation of tumors in many organs, including the prostate, ${ }^{73,74}$ liver ${ }^{75,76}$ breast, ${ }^{77}$ bone, ${ }^{78}$ pancreas,${ }^{43}$ and uterus,${ }^{79}$ or for thermal coagulation of blood vessels. ${ }^{80}$

Suzuki et al reported that a combination of nanobubbles and ultrasound could permeabilize cancer cells and potentiate the cytotoxicity of cisplatin and 5-fluorouracil ${ }^{12}$ in $293 \mathrm{~T}$ human kidney, MCF7 human breast adenocarcinoma,
EMT6 murine mammary carcinoma, and colon 26 murine rectum carcinoma cell lines. Under optimal conditions, nanobubbles (containing albumin or lipid, 10\%, v/v) combined with ultrasound (frequency $945 \mathrm{kHz}$, duty cycle ratio $20 \%-80 \%$, pressure $0.96 \mathrm{mPa}$ ) produced significant cytotoxicity that was not seen with either ultrasound or the drugs used alone. Cytotoxicity could be further enhanced by increasing the duty cycle ratio up to $80 \%$. Rapid collapse of the nanobubbles when combined with ultrasound, led the authors to hypothesize that subnanobubbles, ie, cavitation bubbles, were produced by collapse of the nanobubbles and the shock waves generated by bubble cavitation, leading to transient membrane permeability, followed by entry of plasmid DNA and/or drugs.

\section{Influencing factors and problems Ultrasound wave and drug delivery}

The characteristics of the ultrasound wave, ie, number of cycles per ultrasound pulse, peak negative pressure, and frequency, play an important role in ultrasonic drug delivery. 
In most reports of URDDS, the frequency of ultrasound waves is set at $1 \mathrm{MHz}$ because this frequency allows microbubbles in the 1-3 $\mu \mathrm{m}$ size range to respond to ultrasound. An ultrasound contrast agent shows inertial cavitation at higher acoustic pressure (above approximately $500 \mathrm{kPa}$ ), ${ }^{81}$ that may result in formation of shockwaves and microjets, ${ }^{82}$ generate a temporary pore in the cell membrane, and facilitate drug delivery to the cytoplasm of the cell. ${ }^{83,84}$ If lower acoustic pressures are used (mechanical index $<0.05-0.1$ ), the bubbles oscillate linearly and the reflected frequency is the same as that of the frequency transmitted (Figure 5). If bubbles are located near the cell membrane, gentle oscillation may cause the cell membrane to become unstable, thereby enhancing endocytosis. ${ }^{81,85}$ Increased acoustic pressure $(0.1<$ mechanical index $<0.3)$ will cause nonlinear expansion and compression of the microbubbles, causing the bubbles to become more resistant to compression than to expansion. This is known as noninertial cavitation (Figure 6A), which results in emission of nonlinear harmonic signals. ${ }^{86}$ Harmonic imaging with microbubbles can be used to enhance the bubble-to-tissue backscatter signal ratio. ${ }^{2}$ Higher acoustic pressure (mechanical index $>0.3-0.6$ ) will cause expansion, compression, and disruption of the microbubbles (Figure 6B). This inertial cavitation caused microstreams or microjets to form near bubbles used as flashreplenishment in a diagnostic reperfusion study (Figure 6C). ${ }^{87}$ These microstreams can reach a peak velocity of $700 \mathrm{~m} / \mathrm{sec}$,

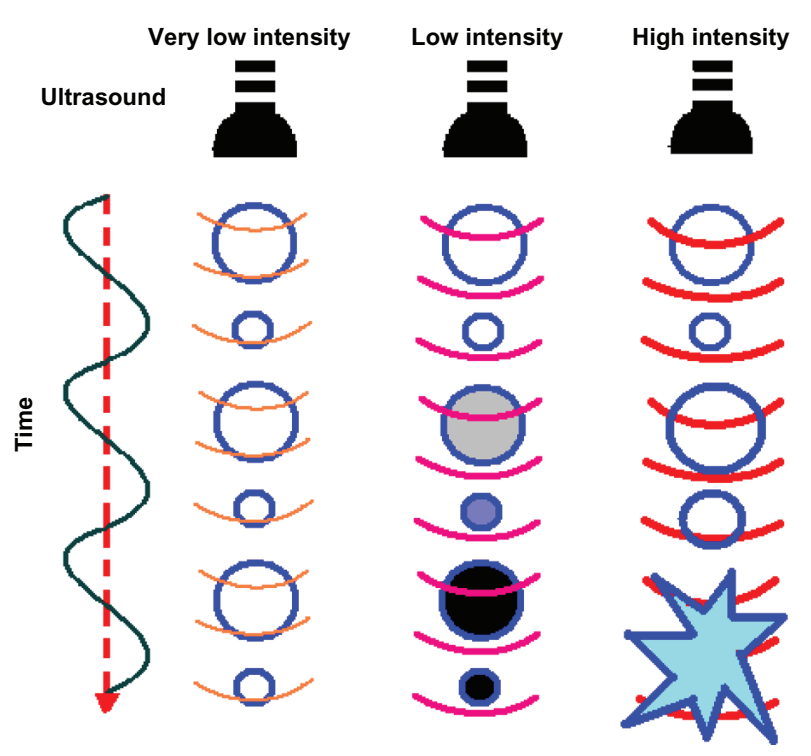

Figure 5 Scheme showing microbubble behavior in acoustic fields. Notes: At very low intensity, ultrasound induces linear oscillation of the microbubble. At low intensity, ultrasound induces oscillation of the microbubble with a gradual increase in microbubble diameter until it reaches a resonant diameter, at which point stable oscillation occurs. At high intensity, ultrasound causes a rapid increase in the diameter of the microbubble for a few cycles, which induces bubble disruption. causing formation of transient pores which increase the permeability of the cell membrane. ${ }^{88}$

Another important parameter is the number of acoustic cycles (ie, acoustic oscillations per ultrasound pulse). Bubbles will oscillate at lower pressures when 100 cycles are used. However, when more cycles are used in combination with higher pressures, the bubbles are destroyed immediately. ${ }^{89}$

\section{Characteristics of URDDS in drug delivery}

The efficiency of URDDS in targeted therapy can be affected by many factors, including the parameters used in ultrasound exposure, the characteristics of the ultrasound contrast agent, the concentration and molecular weight of the therapeutics loaded into the system, and the physiological characteristics of the disease being treated. In this section, we summarize the characteristics most likely to affect the efficiency of targeted URDDS.

\section{Exposure parameters}

To maximize drug release from URDDS, the parameters used for ultrasound exposure must be carefully chosen. Most of the parameters used in ultrasound have been investigated in this regard, with some promising results.

Yeh and $\mathrm{Su}$ reported the effects of acoustic parameters on destruction of the ultrasound contrast agent. ${ }^{90}$ In their experiments, they introduced three insonation parameters, ie, acoustic pressure $(0-1 \mathrm{mPa})$, pulse frequency $(1,2.25,5$, and $7.5 \mathrm{MHz}$ ) and pulse length (1-10 cycles). The percentage of the ultrasound contrast agent that survived decreased with decreasing pulse frequency and with increasing transmission acoustic pressure and pulse length. Further, the extent of destruction of the ultrasound contrast agent was not related to the mechanical index.

$\mathrm{Xu}$ et al developed a novel strategy to enhance the effect of cavitation. ${ }^{91}$ In their study, targeting of tumor tissue was initiated by a short, high-intensity sequence of pulses and sustained by lower intensity pulses.

Zhu et al used different pulse periods $(0.5 \mathrm{msec}, 1 \mathrm{msec}$, $3.3 \mathrm{~ms}, 10 \mathrm{msec}, 15 \mathrm{msec}, 33 \mathrm{msec}$, and 0.1 and $1 \mathrm{~second})$ to study peak cavitation activity reached by high-intensity focused ultrasound exposure, ${ }^{92}$ using pulsed high-intensity focused ultrasound $(1.05 \mathrm{MHz})$ with an intensity $2400 \mathrm{~W} / \mathrm{cm}^{2}$ and a 1:1 duty cycle (with on phase equal to off phase). The irradiation time was 2 minutes. The cavitation activity for pulsed high-intensity focused ultrasound peaked at a pulse period of $10 \mathrm{msec}$, and was significantly greater for pulse durations from $2 \mathrm{msec}$ to $20 \mathrm{msec}$ than for other pulse durations. 


\section{A Noninertial cavitation}

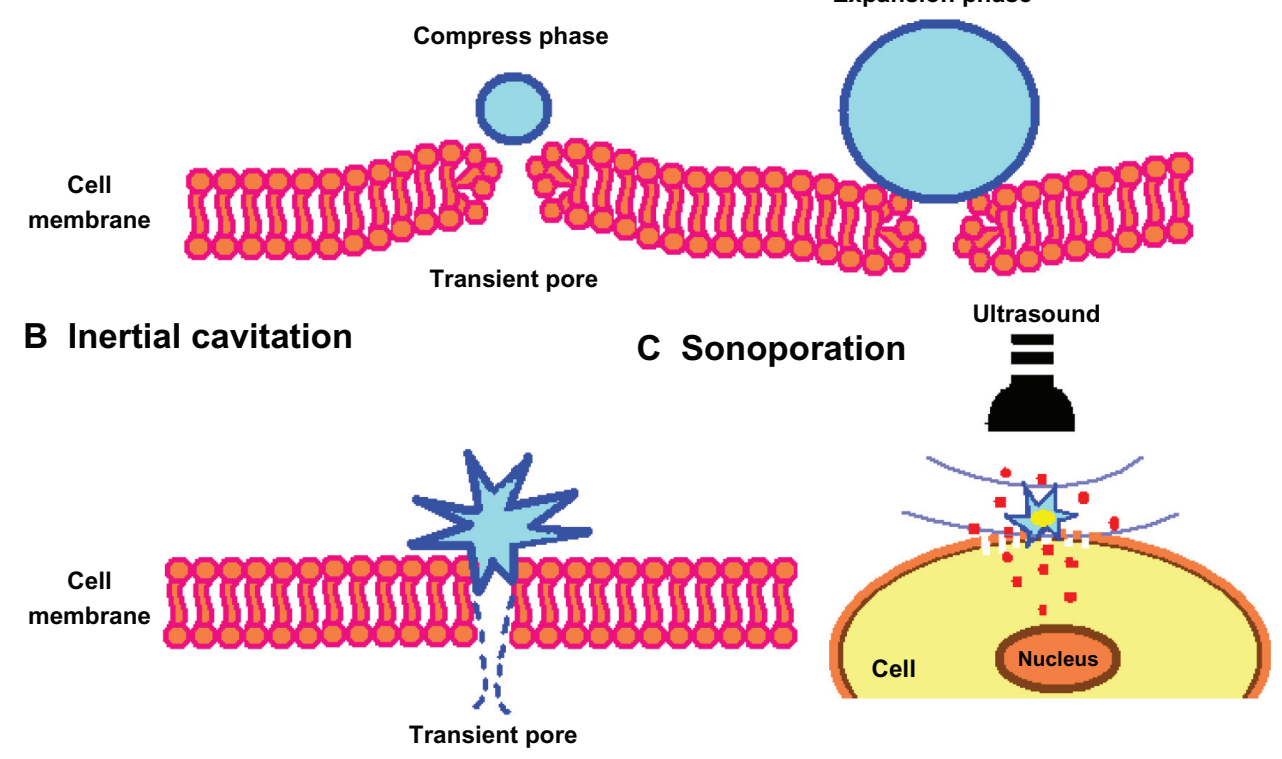

Figure 6 Scheme showing the pore formation in the cell membrane by oscillating or disrupting microbubble. (A) Noninertial cavitation of the microbubble, (B) inertial cavitation causing rupture of the cell membrane, and (C) transmembrane flux of fluid and loaded drugs under sonoporation effect.

To ensure a cavitation effect at the target region, Chen et al used high-speed photography to observe formation of cavitation bubble clouds generated by a high-intensity focused ultrasound transducer in water. ${ }^{93}$ Their results suggest that it might be possible to achieve stable cavitation at the target region in a controllable manner by adjusting the duration of high-intensity focused ultrasound exposure and other physical parameters.

Previous research has shown that the strength of inertial cavitation depends on the initial concentration of the ultrasound contrast agent used. ${ }^{94} \mathrm{Tu}$ et al reported that the strength of inertial cavitation increased significantly with increasing acoustic pressure, concentration of the ultrasound contrast agent, and pulse length, and with decreasing pulserepetition frequency. ${ }^{95}$

\section{Characteristics of ultrasound contrast agents and therapeutic loads}

Being the main components of URDDS, ultrasound contrast agents and therapeutic loads have an important role to play in future therapeutic application of such systems. With regard to ultrasound contrast agents, important factors affecting the efficiency of drug delivery include concentration, gas encapsulated, components used in the shell, surface modification, and size distribution. Chen et al compared the thresholds for ultrasonic destruction of three specific contrast agents, ie, Sonazoid, Optison ${ }^{\circledR}$ (GE Healthcare, Chalfont, UK), and biSpheres ${ }^{\circledR}$ (Point Biomedical Corporation, San Carlos, CA, USA). ${ }^{96}$ Albumin-shelled Optison and surfactant-shelled Sonazoid had low fragmentation thresholds (mean 0.13 and $0.15 \mathrm{MPa}$ at $1.1 \mathrm{MHz}$, and mean 0.48 and $0.58 \mathrm{MPa}$ at $3.5 \mathrm{MHz}$, respectively), while polymer-shelled biSpheres had a significantly higher threshold (mean 0.19 and $0.23 \mathrm{MPa}$ ) for thin-shelled and thick-shell biSpheres (1.1 MHz, 0.73, and $0.96 \mathrm{MPa}$ of thin-shell and thick-shell biSpheres at $3.5 \mathrm{MHz}$, respectively). At comparable initial concentrations, surfactant-shelled Sonazoid produced a much higher inertial cavitation effect than biSpheres or Optison after destruction of the shell. Thick-shelled biSpheres had the highest fragmentation threshold. The propensity of the bubbles to undergo inertial cavitation depended on the properties of the gas and shell used in the ultrasound contrast agents. According to another report, Optison had a larger effect in terms of increasing the permeability of the blood-brain barrier than Definity ${ }^{\circledR}$ (Lantheus Medical Imaging, North Billerica, MA, USA) when the same pressure amplitude was used. ${ }^{97}$

The concentration, molecular weight, and surface charge on the loaded therapeutic agent are also critical determinants of successful drug delivery. For instance, therapeutics with low molecular weight can be easily encapsulated into microbubbles, enabling efficient delivery or transfection. When using URDDS for gene delivery, Duvshani-Eshet and Machluf reported that increasing the DNA concentration 
contributed to increased total gene expression, but did not necessarily improve transfection efficiency ${ }^{98}$

\section{Other characteristics of URDDS in drug delivery}

Undoubtedly, there are further characteristics that may facilitate the use of URDDS. For example, Miller et al found that the ultrasound-induced cavitation effect was influenced by the amount of gas dissolved in the medium. ${ }^{99}$ Further, Brotchie et al identified a strong correlation between the radius of the bubbles used and the concentration of gas dissolved in the cavitation medium. ${ }^{100}$ They also observed an auxiliary function of the electrolyte concentration in the medium.

Although ultrasound contrast agents can be used directly as carriers for therapeutic agents, their gas-nuclear structure limits the space available for loading drugs, especially macromolecules. Nanoscale particles have advantages for drug targeted delivery. Compared with ultrasound contrast agents, nanoscale particles provide both an abundant surface area for modification of particles and an internal volume capable of encapsulating drugs. As mentioned earlier, liposomes, microemulsions, nanodroplets, and polymeric micelles can be used in URDDS to facilitate drug delivery. For example, Chappell et al have reported that nanoparticles loaded with fibroblast growth factor-2 via ultrasonic destruction of microbubbles represent an effective and minimally invasive strategy for targeted stimulation of therapeutic arteriogenesis. ${ }^{101}$ Further, Marin et al have used Pluronic micelles combined with pulsed ultrasound to enhance uptake of doxorubicin. ${ }^{17}$

\section{Problems}

One important shortcoming of ultrasound is that it is strongly attenuated by bone. Large surface area phase arrays and information derived from modern imaging methods may correct the distortion of ultrasound waves produced by the skull to expose the brain tissue by the focal, trans-skull ultrasound. Recently developed clinical ultrasound systems focused using magnetic resonance imaging may make it possible to deliver therapeutics through the intact skull to targeted regions in the brain, and encouraging results in this regard have been seen in animal experiments. ${ }^{102}$

Meanwhile, the molecular mechanism underlying the DNA damage induced by URDDS remains subtle and elusive, and needs further study. Furusawa et al ${ }^{103}$ found that Akt, a substrate of ataxia telangiectasia-mutated and DNA-dependent protein kinase (ATM/DNA-PK), was phosphorylated to the active form in U937 and Molt-4 cell lines without p53 when exposed to ultrasound. Furusawa et al ${ }^{104}$ observed induction of apoptosis in cancer cells, which strongly supports involvement of a purely mechanical mechanism. These researchers were the first to demonstrate that exposure to ultrasound at even a moderate level of intensity has genotoxic potential because of its ability to damage DNA in cancer cell lines.

\section{Perspectives}

URDDS are now a hot topic in drug delivery system research, and the promising results reported so far have encouraged us to shift our attention from fundamental research to potential clinical application of these novel systems, with a focus on the following possibilities.

\section{Theranostics}

Theranostics is a promising technique combining therapy and diagnosis via medical imaging, such as in ultrasound-guided magnetic resonance imaging. ${ }^{105}$ An ultrasound contrast agent can be loaded with $\mathrm{FeO}_{2}{ }^{106}$ or other magnetic nanoparticles to provide contrast in magnetic resonance imaging. ${ }^{107}$ A breakthrough would be if a drug-loaded ultrasound contrast agent could be developed which visualizes pathophysiological tissues simultaneously. For example, human vascular endothelial growth factor receptor 2-targeted lipopeptide can be incorporated into the microbubble shell to create a molecularly targeted clinical ultrasound contrast agent. ${ }^{108}$ If chemotherapeutics can be loaded into this ultrasound contrast agent, it will achieve the dual function of theranostics, ie, monitoring of tumor angiogenesis and delivering targeted therapy.

\section{Permeabilization of cell membranes for drug transport}

URDDS can offer a nonchemical, nonviral, and noninvasive method for drug transport to target cells. Nearly every stage of transient cavitation, including bubble expansion, collapse, and subsequent shock waves may contribute to membrane permeabilization. ${ }^{109}$ In addition, pores on cell membranes may be lasting for seconds to minutes, ${ }^{110,111}$ and even 24 hours $^{112}$ after exposure to ultrasound. This is beneficial for drugs when they are penetrating cells. Research in which TO-PRO-3-loaded thermosensitive liposomes and microbubbles released TO-PRO-3 in response to heating with high intensity focused ultrasound ${ }^{113}$ has validated this concept. Further, pore formation in the cell membrane promoted uptake of TO-PRO-3 by the target cancer cells. It 
could be even more advantageous to sonoporate the target tissue followed by administration of drug-loaded ultrasound contrast agents.

\section{Targeted therapy for vascular disease}

Because ultrasound contrast agents can be used to image the blood pool, URDDS have been investigated as targeted therapy to the vasculature, including thrombolysis, ${ }^{114}$ lithotripsy, ${ }^{115}$ chemotherapy, ${ }^{116}$ anti-inflammatory treatment, ${ }^{117}$ stem cell transplantation ${ }^{118,119}$ and gene therapy for coronary heart disease. In recent years, some researchers have started investigating URDDS as therapy targeted to the brain. ${ }^{120}$

\section{Transdermal drug delivery}

Three aspects of bubble-stratum corneum interaction have been considered, including shock wave emission, microjet penetration into the stratum corneum, and the impact of the microjet on the stratum corneum. ${ }^{121}$ The most common types of drugs delivered through the skin with high-frequency sonophoresis have been anti-inflammatory medications for joint and muscle pain, with an increasing shift in interest recently from topical steroids to nonsteroidal anti-inflammatory drugs, including diclofenac, ${ }^{122}$ ibuprofen, ${ }^{123}$ ketoprofen, ${ }^{124}$ ketorolac, ${ }^{125}$ and piroxicam. ${ }^{126}$ This may reflect the fact that oral NSAIDs generally cause gastrointestinal side effects, including nausea, heartburn, gastrointestinal ulcers, and nonspecific colitis. ${ }^{127}$ Therefore, the combination of topical NSAID therapy and ultrasound is promising, particularly using high-frequency sonophoresis.

\section{Acknowledgments}

This research was supported by grants from the National Natural Science Fund (81272160, 81071164, 81271584, 81000526), Zhejiang Provincial Natural Science Foundation (LY12H30003, LY12H31003, LQ12H30001, LY12H03001, LY12H18001, Y2110587, Y2090834), Beijing Natural Science Foundation (7112100), Scientific Research Joint Funds of Health Ministry and Zhejiang Province (WKJ2011-2-010), Wenzhou Bureau of Science and Technology (Y20090016, H20110008, Y20110034, S20100049, H20100017, Y20100029), Zhejiang Provincial Foundation for Health Department (2011ZDA017, 2012KYB126, 2012KYA134), Zhejiang Provincial Foundation for Education Department (Y201016664), Zhejiang Provincial Project of Key Scientific Group (2010R50042, 2012R10042-06), and the Major Scientific Project of Guangdong Province (2012A080201010).

\section{Disclosure}

The authors report no conflicts of interest in this work.

\section{References}

1. Timko BP, Dvir T, Kohane DS. Remotely triggerable drug delivery systems. Adv Mater. 2010;2:4925-4943.

2. Mulvagh SL, DeMaria AN, Feinstein SB, et al. Contrast echocardiography: current and future applications. J Am Soc Echocardiogr. 2000;13:331-342.

3. Bouakaz A, Versluis M, de Jong N. High-speed optical observations of contrast agent destruction. Ultrasound Med Biol. 2005;31:391-399.

4. Torchilin VP. Targeted pharmaceutical nanocarriers for cancer therapy and imaging. AAPS J. 2007;9:E128-E147.

5. Schroeder A, Honen R, Turjeman K, Gabizon A, Kost J, Barenholz Y. Ultrasound triggered release of cisplatin from liposomes in murine tumors. J Control Release. 2009;137:63-68.

6. Zhao YZ, Luo YK, Lu CT, et al. Phospholipids-based microbubbles sonoporation pore size and reseal of cell membrane cultured in vitro. J Drug Target. 2008;16:18-25.

7. Rapoport NY, Christensen DA, Fain HD, Barrows L, Gao Z. Ultrasound-triggered drug targeting of tumor in vitro and in vivo. Ultrasonics. 2004;42:943-950.

8. Otani K, Yamahara K, Ohnishi S, Obata H, Kitamura S, Nagaya N. Nonviral delivery of siRNA into mesenchymal stem cells by a combination of ultrasound and microbubbles. J Control Release. 2009;133:146-153.

9. Suzuki R, Oda Y, Utoguchi N, Maruyama K. Progress in the development of ultrasound-mediated gene delivery systems utilizing nano- and microbubbles. J Control Release. 2011;149:36-41.

10. Zhao Y, Lu C, Fu H, et al. Phospholipid-based ultrasonic microbubbles for loading protein and ultrasound-triggered release. Drug Dev Ind Pharm. 2009;35:1121-1127.

11. Wang Y, Li X, Zhou Y, Huang P, Xu Y. Preparation of nanobubbles for ultrasound imaging and intracelluar drug delivery. Int $J$ Pharm. 2010;384:148-153.

12. Suzuki M, Koshiyama K, Shinohara F, et al. Nanobubbles enhanced drug susceptibility of cancer cells using ultrasound. International Congress Series. 2005;1284:338-339.

13. Du L, Jin Y, Zhou W, Zhao J. Ultrasound-triggered drug release and enhanced anticancer effect of doxorubicin-loaded poly (D,L-lactideco-glycolide)-methoxy-poly(ethylene glycol) nanodroplets. Ultrasound Med Biol. 2011;37:1252-1258.

14. Ibsen S, Benchimol M, Simberg D, Schutt C, Steiner J, Esener S. A novel nested liposome drug delivery vehicle capable of ultrasound triggered release of its payload. J Control Release. 2011;155:358-366.

15. Zhao Y, Dai D, Lu C, et al. Using acoustic cavitation to enhance chemotherapy of DOX liposomes: experiment in vitro and in vivo. Drug Dev Ind Pharm. 2012;38:1090-1098.

16. Medina J, Salvado A, del Pozo A. Use of ultrasound to prepare lipid emulsions of lorazepam for intravenous injection. Int $J$ Pharm. 2001;216:1-8.

17. Marin A, Muniruzzaman M, Rapoport N. Acoustic activation of drug delivery from polymeric micelles: effect of pulsed ultrasound. J Control Release. 2001;71:239-249.

18. Rapoport N. Combined cancer therapy by micellar-encapsulated drug and ultrasound. Int J Pharm. 2004;277:155-162.

19. Marin A, Sun H, Husseini GA, Pitt WG, Christensena DA, Rapoport NY. Drug delivery in Pluronic micelles: effect of highfrequency ultrasound on drug release from micelles and intracellular uptake. J Control Release. 2002;84:39-47.

20. Suzuki R, Namai E, Oda Y, et al. Cancer gene therapy by IL-12 gene delivery using liposomal bubbles and tumoral ultrasound exposure. $J$ Control Release. 2010;142:245-250.

21. Negishi Y, Endo Y, Fukuyama T, et al. Delivery of siRNA into the cytoplasm by liposomal bubbles and ultrasound. $J$ Control Release. 2008;132:124-130.

22. Rapoport NY, Kennedy AM, Shea JE, Scaife CL, Nam K-H. Controlled and targeted tumor chemotherapy by ultrasound-activated nanoemulsions/microbubbles. J Control Release. 2009;138:268-276. 
23. Harada $\mathrm{Y}$, Ogawa $\mathrm{K}$, Irie $\mathrm{Y}$, et al. Ultrasound activation of $\mathrm{TiO}_{2}$ in melanoma tumors. J Control Release. 2011;149:190-195.

24. Lee M-H, Lin H-Y, Chen H-C, Thomas JL. Ultrasound mediates the release of curcumin from microemulsions. Langmuir. 2008;24: 1707-1713.

25. Eisenbrey JR, Burstein OM, Kambhampati R, Forsberg F, Liu JB, Wheatley MA. Development and optimization of a doxorubicin loaded poly(lactic acid) contrast agent for ultrasound directed drug delivery. J Control Release. 2010;143:38-44.

26. Lu C, Zhao Y, Wu Y, et al. Experiment on enhancing antitumor effect of intravenous epirubicin hydrochloride by acoustic cavitation in situ combined with phospholipid-based microbubbles. Cancer Chemother Pharmacol. 2011;68:343-348.

27. Li P, Zheng Y, Ran H, et al. Ultrasound triggered drug release from 10-hydroxycamptothecin-loaded phospholipid microbubbles for targeted tumor therapy in mice. $J$ Control Release. 2012;162:349-354.

28. Lu C, Zhao Y, Gao H, et al. Comparing encapsulation efficiency and ultrasound-triggered release for protein between phospholipid-based microbubbles and liposomes. J Microencapsul. 2010;27:115-121.

29. Zhao Y, Lu C, Li X, et al. Improving the cardio protective effect of aFGF in ischemic myocardium with ultrasound-mediated cavitation of heparin modified microbubbles: preliminary experiment. J Drug Target. 2012;20:623-631.

30. Yoon CS, Park JH. Ultrasound-mediated gene delivery. Expert Opin Drug Deliv. 2010;7:321-330.

31. Haag P, Frauscher F, Gradl J, et al. Microbubble-enhanced ultrasound to deliver an antisense oligodeoxynucleotide targeting the human androgen receptor into prostate tumours. J Steroid Biochem Mol Biol. 2006;102: 103-113.

32. Zhao Y, Lu C. Factors that affect the efficiency of antisense oligodeoxyribonucleotide transfection by insonated gas-filled lipid microbubbles. J Nanopart Res. 2008;10:449-454.

33. Nomikou N, McHale AP. Exploiting ultrasound-mediated effects in delivering targeted, site-specific cancer therapy. Cancer Lett. 2010;296: 133-143.

34. Bioley G, Lassus A, Bussat P, Terrettaz J, Tranquart F, Corthésy B. Gas-filled microbubble-mediated delivery of antigen and the induction of immune responses. Biomaterials. 2012;33:5935-5946.

35. Lima EG, Durney KM, Sirsi SR, et al. Microbubbles as biocompatible porogens for hydrogel scaffolds. Acta Biomater. 2012;8:4334-4341.

36. Seto JE, Polat BE, Lopez RFV, Blankschtein D, Langer R. Effects of ultrasound and sodium lauryl sulfate on the transdermal delivery of hydrophilic permeants: comparative in vitro studies with full-thickness and split-thickness pig and human skin. $J$ Control Release. 2010;145 26-32.

37. Polat BE, Hart D, Langer R, Blankschtein D. Ultrasound-mediated transdermal drug delivery: mechanisms, scope, and emerging trends. $J$ Control Release. 2011;152:330-348.

38. Burgess A, Huang Y, Querbes W, Sah DW, Hynynen K. Focused ultrasound for targeted delivery of siRNA and efficient knockdown of Htt expression. J Control Release. 2012;163:125-129.

39. Jin $\mathrm{H}$, Tan $\mathrm{H}$, Zhao L, et al. Ultrasound-triggered thrombolysis using urokinase-loaded nanogels. Int J Pharm. 2012;434:384-390.

40. Zhou XB, Qin H, Li J, et al. Platelet-targeted microbubbles inhibit re-occlusion after thrombolysis with transcutaneous ultrasound and microbubbles. Ultrasonics. 2011;51:270-274.

41. Vykhodtseva N, McDannold N, Hynynen K. Progress and problems in the application of focused ultrasound for blood-brain barrier disruption. Ultrasonics. 2008;48:279-296.

42. Liu H-L, Hua M-Y, Chen P-Y, et al. Blood-brain barrier disruption with focused ultrasound enhances delivery of chemotherapeutic drugs for glioblastoma treatment. Radiology. 2010;255:415-425.

43. Rapoport N, Kennedy AM, Shea JE, Scaife CL, Nam K-H. Ultrasonic nanotherapy of pancreatic cancer: lessons from ultrasound imaging. Mol Pharm. 2009;7:22-31.

44. Ferrara K, Pollard R, Borden M. Ultrasound microbubble contrast agents: fundamentals and application to gene and drug delivery. Annu Rev Biomed Eng. 2007;9:415-447.
45. Kabalnov A, Klein D, Pelura T, Schutt E, Weers J. Dissolution of multicomponent microbubbles in the bloodstream: 1. Theory. Ultrasound Med Biol. 1998;24:739-749.

46. Korenaga K, Korenaga M, Furukawa M, Yamasaki T, Sakaida I. Usefulness of Sonazoid contrast-enhanced ultrasonography for hepatocellular carcinoma: comparison with pathological diagnosis and superparamagnetic iron oxide magnetic resonance images. J Gastroenterol. 2009;44:733-741.

47. Watanabe R, Matsumura M, Munemasa T, Fujimaki M, Suematsu M. Mechanism of hepatic parenchyma-specific contrast of microbubblebased contrast agent for ultrasonography: microscopic studies in rat liver. Invest Radiol. 2007;42:643-651.

48. Qin S, Caskey CF, Ferrara KW. Ultrasound contrast microbubbles in imaging and therapy: physical principles and engineering. Phys Med Biol. 2009;54:R27-R57.

49. Azmin M, Mohamedi G, Edirisinghe M, Stride EP. Dissolution of coated microbubbles: the effect of nanoparticles and surfactant concentration. Mater Sci Eng C Mater Biol Appl. 2012;32:2654-2658.

50. Rapoport N, Nam KH, Gupta R, et al. Ultrasound-mediated tumor imaging and nanotherapy using drug loaded, block copolymer stabilized perfluorocarbon nanoemulsions. J Control Release. 2011;153:4-15.

51. Sheeran PS, Luois S, Dayton PA, Matsunaga TO. Formulation and acoustic studies of a new phase-shift agent for diagnostic and therapeutic ultrasound. Langmuir. 2011;27:10412-10420.

52. Fang J, Nakamura H, Maeda H. The EPR effect: unique features of tumor blood vessels for drug delivery, factors involved, and limitations and augmentation of the effect. Adv Drug Deliv Rev. 2011;63:136-151.

53. Sheeran PS, Wong VP, Luois S, et al. Decafluorobutane as a phasechange contrast agent for low-energy extravascular ultrasonic imaging. Ultrasound Med Biol. 2011;37:1518-1530.

54. Zhao Y, Sun C, Lu C, et al. Characterization and anti-tumor activity of chemical conjugation of doxorubicin in polymeric micelles (DOX-P) in vitro. Cancer Lett. 2011;311:187-194.

55. Mitragotri S. Sonophoresis: a 50-year journey. Drug Discov Today. 2004;9:735-736.

56. Mitragotri S, Blankschtein D, Langer R. Transdermal drug delivery using low frequency sonophoresis. Pharm Res. 1996;13:411-420.

57. Gaertner W. Frequency dependence of ultrasonic cavitation. J Acoust Soc Am. 1954;26:977-980.

58. Kushner J, Kim D, So P, Blankschtein D, Langer R. Dual-channel twophoton microscopy study of transdermal transport in skin treated with low-frequency ultrasound and a chemical enhancer. $J$ Invest Dermatol. 2007; 127:2832-2846.

59. Alvarez-Román R, Merino G, Kalia Y, Naik A, Guy R. Skin permeability enhancement by low frequency sonophoresis: lipid extraction and transport pathways. J Pharm Sci. 2003;92:1138-1146.

60. Polat B, Figueroa P, Blankschtein D, Langer R. Transport pathways and enhancement mechanisms within localized and non-localized transport regions in skin treated with low-frequency sonophoresis and sodium lauryl sulfate. J Pharm Sci. 2011;100:512-529.

61. Wolloch L, Kost J. The importance of microjet vs shock wave formation in sonophoresis. J Control Release. 2010;148:204-211.

62. Lee S, Choi K, Menon G, et al. Penetration pathways induced by low-frequency sonophoresis with physical and chemical enhancers: iron oxide nanoparticles versus lanthanum nitrates. J Invest Dermatol. 2010;130:1063-1072.

63. Ueda H, Mutoh M, Seki T, Kobayashi D, Morimoto Y. Acoustic cavitation as an enhancing mechanism of low-frequency sonophoresis for transdermal drug delivery. Biol Pharm Bull. 2009;32:916-920.

64. Lavon I, Grossman N, Kost J, Kimmel E, Enden G. Bubble growth within the skin by rectified diffusion might play a significant role in sonophoresis. J Control Release. 2007;117:246-255.

65. Morimoto Y, Mutoh M, Ueda H, et al. Elucidation of the transport pathway in hairless rat skin enhanced by low frequency sonophoresis based on the solute-water transport relationship and confocal microscopy. J Control Release. 2005;103:587-597.

66. Spierings E, Brevard J, Katz N. Two-minute skin anesthesia through ultrasound pretreatment and iontophoretic delivery of a topical anesthetic: a feasibility study. Pain Med. 2008;9:55-59. 
67. Brown M, Martin G, Jones S, Akomeah F. Dermal and transdermal drug delivery systems: current and future prospects. Drug Deliv. 2006;13: 175-187.

68. Tang H, Blankschtein D, Langer R. Prediction of steady-state skin permeabilities of polar and nonpolar permeants across excised pig skin based on measurements of transient diffusion: characterization of hydration effects on the skin porous pathway. J Pharm Sci. 2002;91: 1891-1907.

69. Pardridge WM. Advances in cell biology of blood-brain barrier transport. Semin Cell Biol. 1991;2:419-426.

70. McDannold N, Arvanitis CD, Vykhodtseva N, Livingstone MS. Temporary disruption of the blood-brain barrier by use of ultrasound and microbubbles: safety and efficacy evaluation in rhesus macaques. Cancer Res. 2012;72:3652-3663.

71. Uesugi Y, Kawata H, Jo J-i, Saito Y, Tabata Y. An ultrasoundresponsive nano delivery system of tissue-type plasminogen activator for thrombolytic therapy. J Control Release. 2010;147:269-277.

72. Diederich CJ, Hynynen K. Ultrasound technology for hyperthermia. Ultrasound Med Biol. 1999;25:871-887.

73. Chapelon JY, Ribault M, Vernier F, Souchon R, Gelet A. Treatment of localised prostate cancer with transrectal high intensity focused ultrasound. Eur J Ultrasound. 1999;9:31-38.

74. Gelet A, Chapelon JY, Poissonnier L, et al. Local recurrence of prostate cancer after external beam radiotherapy: early experience of salvage therapy using high-intensity focused ultrasonography. Urology. 2004;63:625-629.

75. Kohrmann KU, Michel MS, Gaa J, Marlinghaus E, Alken P. High intensity focused ultrasound as noninvasive therapy for multifocal renal cell carcinoma: case study and review of the literature. J Urol. 2002;167:2397-2403.

76. Wu F, Wang ZB, Chen WZ, et al. Extracorporeal high intensity focused ultrasound ablation in the treatment of patients with large hepatocellular carcinoma. Ann Surg Oncol. 2004;11:1061-1069.

77. Wu F, Wang ZB, Cao YD, et al. A randomised clinical trial of highintensity focused ultrasound ablation for the treatment of patients with localised breast cancer. Br J Cancer. 2003;89:2227-2233.

78. Chen W, Wang Z, Wu F, et al. High intensity focused ultrasound in the treatment of primary malignant bone tumor. Zhonghua Zhong Liu Za Zhi. 2002;24:612-615. Chinese.

79. Chan AH, Fujimoto VY, Moore DE, Martin RW, Vaezy S. An image-guided high intensity focused ultrasound device for uterine fibroids treatment. Med Phys. 2002;29:2611-2620.

80. Vaezy S, Noble ML, Keshavarzi A, et al. Liver hemostasis with high-intensity ultrasound: repair and healing. J Ultrasound Med Biol. 2004;23:217-225.

81. Afadzi M, Davies CD, Hansen YH, et al. Effect of ultrasound parameters on the release of liposomal calcein. Ultrasound Med Biol. 2012;38: 476-486.

82. Ohl CD, Arora M, Ikink R, et al. Sonoporation from jetting cavitation bubbles. Biophys J. 2006;91:4285-4295.

83. Lentacker I, Wang N, Vandenbroucke RE, Demeester J, Smedt SCD, Sanders NN. Ultrasound exposure of lipoplex loaded microbubbles facilitates direct cytoplasmic entry of the lipoplexes. Mol Pharm. 2009;6:457-467.

84. Geers B, Lentacker I, Alonso A, et al. Elucidating the mechanisms behind sonoporation with adeno-associated virus-loaded microbubbles. Mol Pharm. 2011;8:2244-2251.

85. Meijering BD, Juffermans LJ, van Wamel A, et al. Ultrasound and microbubble-targeted delivery of macromolecules is regulated by induction of endocytosis and pore formation. Circ Res. 2009;104:679-687.

86. Unger EC, Hersh E, Vannan M, Matsunaga TO, McCreery T. Local drug and gene delivery through microbubbles. Prog Cardiovasc Dis. 2001;44:45-54.

87. Kalantarinia K, Belcik JT, Patrie JT, Wei K. Real-time measurement of renal blood flow in healthy subjects using contrast-enhanced ultrasound. Am J Physiol Renal Physiol. 2009;297:F1129-F1134.
88. Taniyama Y, Tachibana K, Hiraoka K, et al. Local delivery of plasmid DNA into rat carotid artery using ultrasound. Circulation. 2002;105: 1233-1239.

89. Mannaris C, Averkiou MA. Investigation of microbubble response to long pulses used in ultrasound-enhanced drug delivery. Ultrasound Med Biol. 2012;38:681-691.

90. Yeh CK, Su SY. Effects of acoustic insonation parameters on ultrasound contrast agent destruction. Ultrasound Med Biol. 2008;34: 1281-1291.

91. Xu Z, Fowlkes JB, Cain CA. A new strategy to enhance cavitational tissue erosion using a high-intensity, initiating sequence. IEEE Trans Ultrason Ferroelectr Freq Control. 2006;53:1412-1424.

92. Zhu C, He S, Shan M, Chen J. Study of a peak in cavitation activity from HIFU exposures using TA fluorescence. Ultrasonics. 2006; 44 Suppl 1:e349-e351.

93. Chen H, Li X, Wan M. The inception of cavitation bubble clouds induced by high-intensity focused ultrasound. Ultrasonics. 2006; 44 Suppl 1:e427-e429.

94. Chen WS, Brayman AA, Matula TJ, Crum LA. Inertial cavitation dose and hemolysis produced in vitro with or without Optison. Ultrasound Med Biol. 2003;29:725-737.

95. Tu J, Matula TJ, Brayman AA, Crum LA. Inertial cavitation dose produced in ex vivo rabbit ear arteries with Optison by 1-MHz pulsed ultrasound. Ultrasound Med Biol. 2006;32:281-288.

96. Chen WS, Matula TJ, Brayman AA, Crum LA. A comparison of the fragmentation thresholds and inertial cavitation doses of different ultrasound contrast agents. J Acoust Soc Am. 2003;113:643-651.

97. McDannold N, Vykhodtseva N, Hynynen K. Use of ultrasound pulses combined with definity for targeted blood-brain barrier disruption: a feasibility study. Ultrasound Med Biol. 2007;33: 584-590.

98. Duvshani-Eshet M, Machluf M. Therapeutic ultrasound optimization for gene delivery: a key factor achieving nuclear DNA localization. $J$ Control Release. 2005;108:513-528.

99. Miller MW, Everbach EC, Miller WM, Battaglia LF. Biological and environmental factors affecting ultrasound-induced hemolysis in vitro: 2. Medium dissolved gas (pO2) content. Ultrasound Med Biol. 2003;29:93-102.

100. Brotchie A, Statham T, Zhou M, Dharmarathne L, Grieser F, Ashokkumar M. Acoustic bubble sizes, coalescence, and sonochemical activity in aqueous electrolyte solutions saturated with different gases. Langmuir. 2010;26:12690-12695.

101. Chappell JC, Song J, Burke CW, Klibanov AL, Price RJ. Targeted delivery of nanoparticles bearing fibroblast growth factor-2 by ultrasonic microbubble destruction for therapeutic arteriogenesis. Small. 2008;4:1769-1777.

102. Hynynen K, Clement G, McDannold N, Vykhodtseva N. The feasibility of noninvasive image-guided treatments of brain disodereds by focused ultrasound. J Acoust Soc Am. 2004;115:24-46.

103. Furusawa Y, Fujiwara Y, Hassan MA, et al. Inhibition of DNA-dependent protein kinase promotes ultrasound-induced cell death including apoptosis in human leukemia cells. Cancer Lett. 2012;322: 107-112.

104. Furusawa Y, Fujiwara Y, Campbell P, et al. DNA double-strand breaks induced by cavitational mechanical effects of ultrasound in cancer cell lines. PLoS One. 2012; 7:e29012.

105. Lammers T, Aime S, Hennink WE, Storm G, Kiessling F. Theranostic nanomedicine. Acc Chem Res. 2011;44:1029-1038.

106. Liu Z, Lammers T, Ehling J, et al. Iron oxide nanoparticle-containing microbubble composites as contrast agents for MR and ultrasound dual-modality imaging. Biomaterials. 2011;32:6155-6163.

107. Lim YT, Cho MY, Kang JH, et al. Perfluorodecalin/[InGaP/ZnS quantum dots] nanoemulsions as $19 \mathrm{~F} \mathrm{MR/optical} \mathrm{imaging} \mathrm{nanoprobes}$ for the labeling of phagocytic and nonphagocytic immune cells. Biomaterials. 2010;31:4964-4971.

108. Pochon S, Tardy I, Bussat P, et al. BR55: a lipopeptide-based VEGFR2targeted ultrasound contrast agent for molecular imaging of angiogenesis. Invest Radiol. 2010;45:89-95. 
109. Sundaram J, Mellein BR, Mitragotri S. An experimental and theoretical analysis of ultrasound-induced permeabilization of cell membranes. Biophys J. 2003;84:3087-3101.

110. Schlicher RK, Hutcheson JD, Radhakrishna H, Apkarian RP, Prausnitz MR. Changes in cell morphology due to plasma membrane wounding by acoustic cavitation. Ultrasound Med Biol. 2010;36: 677-692.

111. van Wamel A, Kooiman K, Emmer M, ten Cate FJ, Versluis M, de Jong N. Ultrasound microbubble induced endothelial cell permeability. J Control Release. 2006;116:e100-e102.

112. Yudina A, Lepetit-Coiffe M, Moonen CT. Evaluation of the temporal window for drug delivery following ultrasound-mediated membrane permeability enhancement. Mol Imaging Biol. 2011;13:239-249.

113. Yudina A, de Smet M, Lepetit-Coiffé M, et al. Ultrasound-mediated intracellular drug delivery using microbubbles and temperaturesensitive liposomes. J Control Release. 2011;155:442-448.

114. Maxwell AD, Cain CA, Duryea AP, Yuan L, Gurm HS, Xu Z. Noninvasive thrombolysis using pulsed ultrasound cavitation therapy - histotripsy. Ultrasound Med Biol. 2009;35:1982-1994.

115. Yoshizawa S, Ikeda T, Ito A, Ota R, Takagi S, Matsumoto Y. High intensity focused ultrasound lithotripsy with cavitating microbubbles. Med Biol Eng Comput. 2009;47:851-860.

116. Gourevich D, Gerold B, Arditti F, et al. Ultrasound activated nanoencapsulated targeted drug delivery and tumour cell poration. Adv Exp Med Biol. 2012;733:135-144.

117. Askari AT, Unzek S, Popovic ZB, et al. Effect of stromal-cell-derived factor 1 on stem-cell homing and tissue regeneration in ischaemic cardiomyopathy. Lancet. 2003;362:697-703.

118. Ghanem A, Steingen C, Brenig F, et al. Focused ultrasound-induced stimulation of microbubbles augments site-targeted engraftment of mesenchymal stem cells after acute myocardial infarction. J Mol Cell Cardiol. 2009;47:411-418
119. Zhong S, Shu S, Wang Z, et al. Enhanced homing of mesenchymal stem cells to the ischemic myocardium by ultrasound-targeted microbubble destruction. Ultrasonics. 2012;52:281-286.

120. Pinton G, Aubry JF, Fink M, Tanter M. Numerical prediction of frequency dependent 3D maps of mechanical index thresholds in ultrasonic brain therapy. Med Phys. 2012;39:455-467.

121. Tezel A, Mitragotri S. Interactions of inertial cavitation bubbles with stratum corneum lipid bilayers during low-frequency sonophoresis. Biophys J. 2003;85:3502-3512.

122. Sharma D, Hanesh M, Yahya A, Mohamed M. Phonophoresis with diclofenac versus ketoprofen for knee joint injuries. Middle East J Int Med. 2009;2:9-12.

123. Meshali M, Abdel-Aleem H, Sakr F, Nazzal S, El-Malah Y. Effect of gel composition and phonophoresis on the transdermal delivery of ibuprofen: in vitro and in vivo evaluation. Pharm Dev Technol. 2011;16:93-101.

124. Kaya K, Delialouglu S, Babadag M, et al. Combined physiotherapy in patients with arthrogenous pain of temporomandibular joint. $J$ Phys Med Rehab Sci. 2010;13:6-14.

125. Yang JH, Kim TY, Lee JH, Yoon SW, Yang KH, Shin SC. Antihyperalgesic and anti-inflammatory effects of ketorolac tromethamine gel using pulsed ultrasound in inflamed rats. Arch Pharm Res. 2008;31:511-517.

126. Meshali M, Abdel-Aleem H, Sakr F, Nazzal S, El-Malah Y. In vitro phonophoresis: effect of ultrasound intensity and mode at high frequency on NSAIDs transport across cellulose and rabbit skin membranes. Pharmazie. 2008;63:49-53.

127. Rainsford KD. Profile and mechanisms of gastrointestinal and other side effects of nonsteroidal anti-inflammatory drugs (NSAIDs). Am J Med. 1999;107:27-35.
International Journal of Nanomedicine

\section{Publish your work in this journal}

The International Journal of Nanomedicine is an international, peerreviewed journal focusing on the application of nanotechnology in diagnostics, therapeutics, and drug delivery systems throughout the biomedical field. This journal is indexed on PubMed Central,

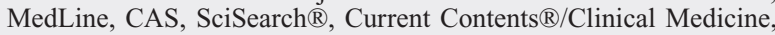

\section{Dovepress}

Journal Citation Reports/Science Edition, EMBase, Scopus and the Elsevier Bibliographic databases. The manuscript management system is completely online and includes a very quick and fair peer-review system, which is all easy to use. Visit http://www.dovepress.com/ testimonials.php to read real quotes from published authors. 